\title{
The NorthGRIP ice-core logging procedure: description and evaluation
}

\author{
Christine Sahøtt HVidberg, ${ }^{1}$ Jørgen Peder Steffensen,,${ }^{1}$ Henrik B. CLAUSEN, ${ }^{1}$ \\ Hitoshi SHOJI, ${ }^{2}$ Joseph KIPFSTUHL ${ }^{3}$ \\ ${ }^{1}$ The Niels Bohr Institute, Department of Geophysics, University of Copenhagen, Juliane Maries Vej 30, DK-2100 Copenhagen, Denmark \\ E-mail: ch@gfy.ku.dk \\ ${ }^{2}$ Department of Civil Engineering, Kitami Institute of Technology, Koen-Cho 165, Kitami 090-8507, Japan \\ ${ }^{3}$ Alfred-Wegener-Institut für Polar- und Meeresforschung, Columbusstrasse, D-2850 Bremerhaven, Germany
}

\begin{abstract}
The ice-core logging procedure used to log the North Greenland Icecore Project (NorthGRIP) ice cores is described. The existence of two deep ice cores, NorthGRIP 1 and 2, drilled $25 \mathrm{~m}$ apart, allows an independent evaluation of the procedure. The logged depths of the NorthGRIP 1 and 2 cores deviate from the length of the unwound drill cable corrected for elongation of the cable when hanging in the hole, by $1.5 \%$ and $<0.5 \%$ at depths of 1371 and $2931 \mathrm{~m}$, respectively. Differences between logged depths of identified layers found in both cores are studied in the depth interval where they overlap. Layers are identified by electrical conductivity measurements and dielectric profiling. The difference between the logged depths of layers identified in both cores increases to $0.5 \mathrm{~m}$ close to the bottom of the NorthGRIP 1 core, which is $<0.5 \mathrm{~mm} \mathrm{~m}^{-1}$ ice core. The comparison between the two cores shows that the NorthGRIP logging procedure is accurate and reproducible. Further, our results show that the temperature conditions and handling of the core during logging are important for obtaining a precise depth.
\end{abstract}

\section{INTRODUGTION}

During the North Greenland Icecore Project (NorthGRIP) deep drilling project at position $75.1^{\circ} \mathrm{N}, 42.3^{\circ} \mathrm{W}$, two deep cores have been retrieved (Dahl-Jensen and others, 2002). The deep drilling commenced in 1996, and in 1997 the drill became stuck after retrieving $1371.80 \mathrm{~m}$ of ice core (NorthGRIP 1). In 1999, drilling started again from the surface. At the end of the 2000 field season, a total of $2931.23 \mathrm{~m}$ of ice core was obtained (NorthGRIP 2), and drilling was continued in 2001. The existence of two deep ice cores, drilled only $25 \mathrm{~m}$ apart, allows comparisons between the cores over the $1371 \mathrm{~m}$ where they overlap. In this paper, we document and evaluate the NorthGRIP logging procedure. We will not discuss the bottom part of NorthGRIP 2, drilled after the 2000 season.

Depth of ice-core samples is the primary information used to present and discuss ice-core data, and a reliable depth is a critical condition for later analyses of ice-core data and for interpretation of direct measurements in the ice (e.g. internal radar reflection layers). This is the first paper to describe and discuss an ice-core logging procedure.

The NorthGRIP logging procedure has been used in several deep drilling projects (Dye-3, GRIP). The set-up and handling has gradually been optimized. Accumulated over hundreds of metres, even minor improvements increase the accuracy. We evaluate the procedure by comparing the logged depth with the independent reading of the cable length for both cores, and by comparing depths of identified layers in both cores down to the bottom depth of the NorthGRIP 1 core. Both cores reach deeper than the socalled brittle zone.

\section{THE LOGGING PROGEDURE}

The goal of an ice-core logging procedure is to obtain a precise depth, to prepare the ice core in an optimal way for later processing and to ensure that depth appears clearly and unambiguously. Effects of breaks must be minimized, and missing ice, though rare, must be handled consistently.

\section{Depth scale}

We measure the depth of the core in metres. For practical reasons, however, the core is divided into bags, defined by 1 $\mathrm{bag}=0.55 \mathrm{~m}$. After processing (sampling and non-destructive measurements), the remaining part of the ice core is stored in boxes. We cut and pack the ice core in marked plastic bags, each containing segments of $0.55 \mathrm{~m}$, which fit precisely into our insulated boxes. If boxes are packed optimally, they preserve temperature when transported or stored in cold rooms.

\section{Normal procedure}

The NorthGRIP ice cores were drilled with the newly developed European Project for Ice Coring in Antarctica (EPICA) drill (Gundestrup and others, 1996) in segments with a maximum length of 4-4.5 m (a run). Before logging, the ice core is cleaned with brushes in order to remove drill fluid, slush, small grains, etc. Logging is done in several steps:

(1) The top of the run is fitted to the bottom of the previous run. This is done by turning one of the cores until the two cores fit to each other. Usually, the cores fit perfectly together. If a run is in more than one piece, the next step is to fit the remaining pieces to each other, starting from 


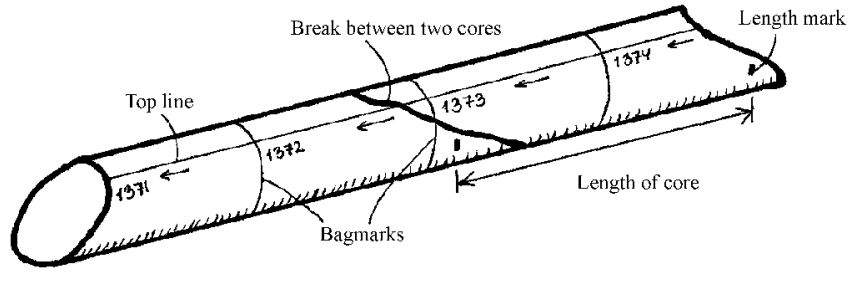

Fig. 1. The normal logging procedure. Two cores are aligned, and fitted to each other. Bags and top line are marked.

the top, so eventually the core is assembled and placed aligned and fitted to the previous run (Fig. 1). A method for handling situations with no fit or missing ice is described in the next subsection.

(2) The length of the core is measured in full centimetres from a length mark at the bottom of the previous run to a new length mark at the bottom of the new run. Length marks are written on the core surface at a distance of $1-2 \mathrm{~cm}$ from the bottom edge of the core in order to ensure that the length mark is not knocked off during the fitting process with the next run. Thus, the length of the core represents the distance along the core between the two successive length marks, not the true length of the new run. The true length of a core can be ambiguous, because top and bottom surfaces are often inclined. After the length is measured, a line is marked along the core (top line, Fig. 1), in order to prevent pieces from being rotated relative to each other. Also arrows indicating the vertically upward direction of the core are drawn at the core surface. We use soft pencils when writing on the core surface.

(3) Bags (length segments of $0.55 \mathrm{~m}$ ) are marked on the core surface. A ruler is placed at the core relative to the last bag mark on the previous core, and new bag marks are written each $0.55 \mathrm{~m}$ along the core. The length from the last bag mark at the bottom to the new length mark is measured; this is the length of the last bag. A simple check is now that the length of the last bag must be in full centimetres. If not, either bag marks or length mark is imprecise and must be corrected before logging proceeds. That the bags are marked and numbered correctly is also checked. Even though most errors would be discovered when the core is packed, it may damage the sampling if, for instance, a bag is marked too short. A simple check is that the accumulated depth (defined as the accumulated depth of the previous length mark + the length of the core) equals the last full bag number at the bottom (as written on the core) $\times 0.55 \mathrm{~m}+$ the length of the last bag.

(4) Finally, the core is rotated in the trough. Bag marks are extended all around the core, and bag numbers are written on the opposite side. Bag numbers are clearly written on all pieces. If there are several pieces, lines marked on the core surface indicate how they fit to each other.

After logging, the core is kept at the logging table, to be used to log the next run, because the bottom part with the length mark is critical for the continuous logging. After logging, the cores are taken to a storage room, where they are stored in troughs in lengths of $1.5-2 \mathrm{~m}$, which are practical sizes to handle. With clearly readable marks on the core, and with an accompanying note of depth and bag interval, the core and its direction can always be identified later in the processing.

\section{Fitting ice cores}

Even though ice cores are often in more than one piece, it is possible to fit the pieces perfectly together. There is no doubt when a perfect fit is found: all small surface irregularities close between the pieces, and they seem to click together. Sometimes, the fitting is a difficult three-dimensional jigsaw puzzle. First priority is, however, to reconstruct the core to a point where the length can be determined (step 2 above), thus securing the subsequent logging. Until this is done, all pieces may be decisive for finding a fit. If it is difficult to decide the best fit, it may help to identify marks from the core catchers (metal devices which keep the core in the drill during pull-up).

Sometimes, no fit exists between two runs; fortunately, this does not occur often. The situation may arise for a number of reasons: a core piece is knocked off during handling and lost; the core is broken into many pieces (e.g. in the brittle zone), and the jigsaw puzzle is difficult to put together; a chunk of ice was left in the hole, and crushed by the drill in the following run, and brought to the surface as pieces on top of the next run. In a no-fit situation, the length of the run must be based on the drillers' information. The drill is hanging in a steel wire. In each run, the length of the unwound cable is reported before and after the core is drilled. If the cores do not fit, the length is defined to be this estimated length, which we believe to be accurate within a few centimetres. Necessity makes this precision acceptable, even though it is significantly lower than with a fit. Regardless of the cause of the missing fit, it is important to save all core pieces. The weight of all the pieces may be used to estimate a minimum length of the original core. This estimate alone is not sufficient for logging, because some ice may be lost.

\section{Handling and set-up}

Here, we will describe the logging set-up for the NorthGRIP 2 ice-core logging, and make some recommendations for handling during the logging process. The set-up has been gradually improved through the NorthGRIP deep drilling project. The basic idea in our set-up is that the core must be logged before it is stored or before it is processed in any way. This is to avoid errors in the order of cores, and also because core dimensions may change due to stress relaxation if the core is stored over a long period of time. Another important principle is that the core should not be taken out of the trough - lifted or separated - before it has been logged. In many cases, the ice at the breaks sticks together (e.g. at breaks formed spontaneously while the core is resting in the trough). If the pieces are separated, it is almost impossible to reassemble them as closely as before. After hundreds of breaks, the accumulated depth may become too long.

Particularly in the brittle zone, breaks often form spontaneously in the core after it is brought to the surface. In the brittle zone, air bubbles at high pressure are transformed into clathrates (Pauer and others, 1999). At NorthGRIP this occurs at 900-1300 m. In this depth interval, high stress concentrations around the air bubbles make the core particularly sensitive to additional stresses caused by temperature gradients and handling. The ice cores are subject to a temperature increase when brought from the hole at a temperature of around $-30^{\circ} \mathrm{C}$ to the surface. In order to reduce 
the number of additional breaks, the ice cores are kept at the lowest temperature possible. When the NorthGRIP 1 icecore drilling was terminated, a new drill trench was excavated for the NorthGRIP 2 drilling, and the old drill trench was free to be used for logging, storing, etc. With no power-consuming activities, this trench stayed cold at temperatures below $-20^{\circ} \mathrm{C}$ during the season, providing optimal logging conditions. The NorthGRIP 1 core, on the other hand, was logged in the drill trench, where the temperature was sometimes up to $-5^{\circ} \mathrm{C}$ during the season.

The core is pushed out of the drill into a core trough, and after inspection the drillers carry the core to the logging table. The core trough is placed in horizontal holders aligned with a permanent set-up of troughs. The ice core is then pushed directly from the core trough into the permanent core trough, where the previous ice core is waiting. After logging, the previous ice core is then pushed on into another detachable core trough at the top end, and carried to an ice-core storage room. We use aluminium core troughs, where the cores slide easily; wooden core troughs do not work as well. The most efficient method of logging ice cores from the brittle zone is to push the core into the permanent trough while keeping all the pieces assembled, and only to turn the previous core, not the new run, until a fit is found between the cores. The latter protects the core against additional breaks during fitting before the total length is measured, which could alter the subsequent logging. Eventually, the core is turned and marked as described above. Accurate alignment of the permanent core troughs, and smooth transitions to the detachable troughs at the ends are also important

\section{EVALUATION OF LOGGING PROGEDURE}

In order to evaluate the reliability and accuracy of the icecore logging procedure, logged depths are compared to the length of the unwound drill cable, which is an independent measure of depth (Fig. 2). The length of the unwound drill cable is measured immediately before drilling, while the drill hangs freely in the hole. In each run, the cable length is reset at the surface, before the drill is lowered into the hole. The length of the cable is measured at the surface by revolutions of a sheave supporting the cable while it is unwound. The sheave is cleaned in every run in order to remove condensation. The uncertainty is approximately $1 \%$. This length does not take into account stretching of the cable due to gravity while it is hanging in the hole. If we assume no temperature dependence, the extension of a wire can be expressed as $\Delta l=(g / E A) l[M+(\rho l / 2)]$, where $g$ is gravity, $E$ is Young's modulus, $A$ is the cross-sectional area of the cable, $l$ is the unwound but non-stretched cable length, $M$ is the mass of the drill corrected for buoyancy when hanging in the drill liquid and $\rho$ is mass per unit length of the cable similarly corrected for buoyancy. The modelled difference between the true depth of the hole and the length of the cable is then $l_{0}-\Delta l$, where $l_{0}$ is an initial offset between the two. The drillholes were commenced from the floor of an inclined trench excavated in the drill trench. The offset is caused by the cable length being reset when the drill hangs at the top of the hole in a depth of around $10 \mathrm{~m}$ (the depth of the inclined trench). We use the given specifications: drill weight $M=150 \mathrm{~kg}$ and cable weight $\rho=0.168 \mathrm{~kg} \mathrm{~m}^{-1}$, both in a liquid with $930 \mathrm{~kg} \mathrm{~m}^{-3}$

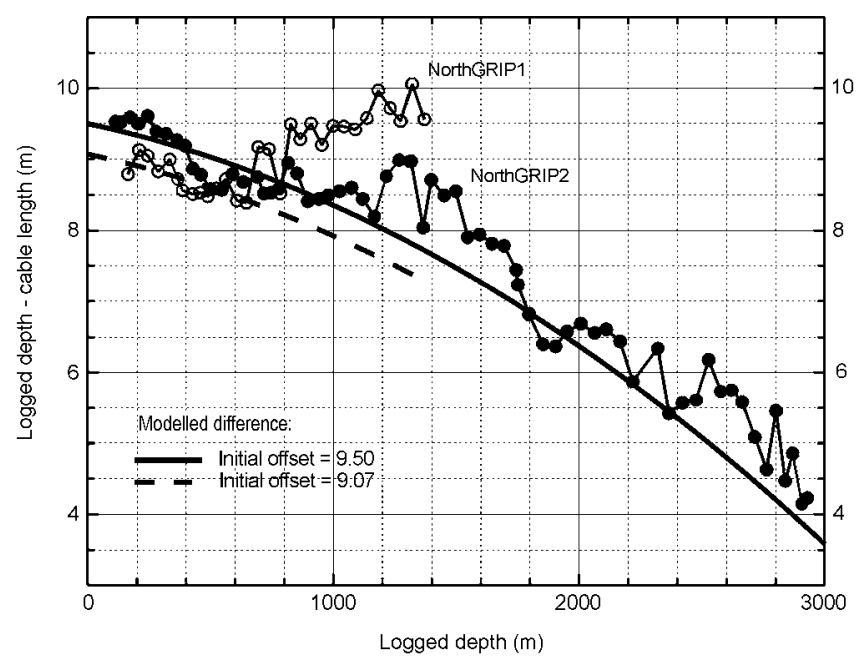

Fig. 2. Comparison between the logged depth and the unwound cable length. Data are plotted for approximately every 15 th run for NorthGRIP 1 (thin line/open circles) and for NorthGRIP 2 (thin line/full circles). The difference between the depth of the hole and cable length is modelled and plotted for two initial offsets of the cable length, which fit the upper $600 \mathrm{~m}$ of the NorthGRIP 1 core (dashed line) and the NorthGRIP 2 core (thick solid line), respectively.

density, and elongation of cable $1 / E A=0.5 \mathrm{~m} \mathrm{~km}^{-1} \mathrm{kN}^{-1}$ (Johnsen and others, 1994; Gundestrup and others, 1996).

The modelled difference between the true depth of the hole and the unwound cable length is plotted in Figure 2. We do not know the offset precisely, but calculate initial offsets of $l_{0}=9.07 \mathrm{~m}$ and $l_{0}=9.50 \mathrm{~m}$ as the best fit to the logged depths in the upper $600 \mathrm{~m}$ of the NorthGRIP 1 and 2 cores, respectively. We use the upper $600 \mathrm{~m}$ to calculate initial offsets, because the core quality is good and it is above the brittle zone. For both cores, the difference between logged depth and cable length is gradually displaced from the modelled curve in the depth interval covering the brittle zone. For NorthGRIP 2, however, the displacement is within around $1 \mathrm{~m}$ down to the bottom depth of $2930 \mathrm{~m}$, and the average departure below $1300 \mathrm{~m}$ depth of the difference between logged depth and cable length from the modelled curve is $0.5 \mathrm{~m}$, i.e. $<0.5 \%$ of the depth. Assuming that the true depth of the hole may be calculated from the cable length, this is the error introduced into the NorthGRIP 2 logging by additional breaks in the brittle zone. For NorthGRIP 1, there is a similar error. It is not possible to calculate this error, as the core does not extend sufficiently far below the brittle zone. From Figure 2, we estimate the error in the NorthGRIP 1 logging due to the brittle zone to be $1-2 \mathrm{~m}$, which is $1.5 \%$ of the depth. The calculation of depth based on cable length does not take into account friction between the cable and the hole, which could affect the apparent mass of the drill and the cable. This effect would decrease $\Delta l$, and thereby make the model fit our data better. A potential systematic error in the depth derived from cable length is due to the fact that the core catchers do not always break the core at the same location in the drilled core. This leads to a varying overestimate of the core length based on cable length of up to $0.1 \mathrm{~m}$, and could explain some of the scatter in the data in Figure 2. At NorthGRIP 2, the cable was changed at $2494 \mathrm{~m}$ depth, but this had no effect on the observed length of the unwound cable.

The reproducibility of the logging procedure is evaluated 


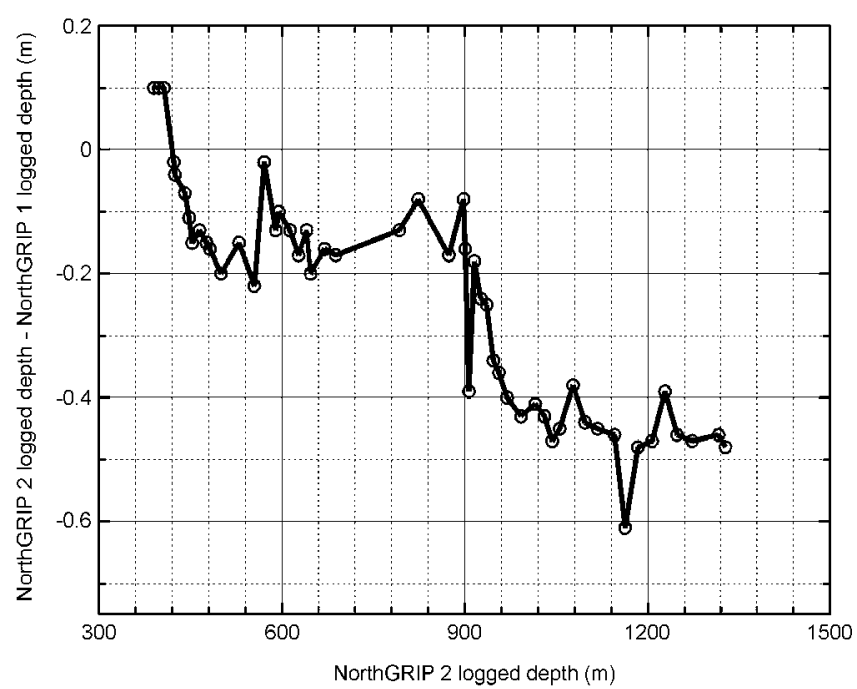

Fig. 3. Comparison between logged depths of horizons identified in both the NorthGRIP 1 and 2 cores (circles/full line). The comparison is over depths of 390-1328 m, which are covered by both cores.

by comparing depths of horizons identified in both the NorthGRIP 1 and 2 cores (Fig. 3). The selected horizons are identified by electrical conductivity measurements (ECM) and dielectric profiling (DEP) measurements of the two cores. At the top, layers in the NorthGRIP 2 core are $0.25 \mathrm{~m}$ deeper than in the NorthGRIP 1 core. The top depth of the first NorthGRIP 1 core run was defined to be the depth of the floor of the inclined trench relative to the surface of undisturbed snow in 1996, which was $9.84 \mathrm{~m}$. When the NorthGRIP 2 drilling commenced in 1999, the top depth was not defined relative to the 1996 summer surface, but to a slightly higher surface. Figure 3 shows that with increasing depth the difference between the cores changes sign, and the deepest layer (at $1328 \mathrm{~m}$ depth) has a logged depth in the NorthGRIP 1 core which is $0.5 \mathrm{~m}$ deeper than in the NorthGRIP 2 core, i.e. from surface to $1328 \mathrm{~m}$ depth the NorthGRIP 1 core is stretched $0.75 \mathrm{~m}$ relative to the NorthGRIP 2 core. The difference between the two cores is $0.4 \%$ relative to the depth, and shows that our logging procedure is accurate and handles possible incompleteness (e.g. no fit or lost ice) consistently. Inclination of the boreholes could affect this comparison. In the NorthGRIP 2 borehole, the inclination increases steadily to $1.25^{\circ}$ in $1371 \mathrm{~m}$ depth. In the NorthGRIP 1 borehole, the inclination was similar, but slightly smaller (personal communication from N. Gundestrup, 2001). This introduces uncertainties of up to $0.1-0.2 \mathrm{~m}$ into the comparison. Based on Figure 2, we conclude that the difference between the core lengths is due to accumulated errors in the NorthGRIP 1 logging compared to NorthGRIP 2. We are able to explain the increased error at NorthGRIP 1 compared to NorthGRIP 2 by optimizations in the logging procedure at NorthGRIP 2, in particular in the temperature conditions during logging (see previous section). Cold temperatures during logging at NorthGRIP 2 prevented many spontaneous breaks from forming. The improved procedure, where the core was pushed from one trough to the next, while the pieces were kept together, further minimized errors introduced by the breaks into the logged depth. Both cores were logged by a shifting team of experienced people.

\section{CONGLUSION}

The NorthGRIP logging procedure has been described. It was used to $\log$ the NorthGRIP 1 and NorthGRIP 2 cores, which were drilled $25 \mathrm{~m}$ apart. Comparisons between logged depth and cable length show that the logging procedure is highly consistent and precise, and yield a depth which is within $1.5 \%$ and $0.5 \%$ of the cable length for the NorthGRIP 1 and 2 cores, respectively. The close agreement also shows that situations with no fit between cores are handled in a consistent way. Assuming that the depth of the hole is accurately measured by the length of the unwound cable corrected for elongation when hanging, we estimate the error in measured depth introduced by additional breaks in the brittle zone to be 1-2 and $0.5 \mathrm{~m}$ for NorthGRIP 1 and 2, respectively. Comparison between reference horizons identified in both cores shows that the difference between logged depths of a layer in the two cores increases to $0.5 \mathrm{~m}$ at $1371 \mathrm{~m}$ depth, which is the bottom of the NorthGRIP 1 core. The difference constitutes $<0.5 \mathrm{~mm} \mathrm{~m}^{-1}$ ice core, showing that the logging procedure is highly reproducible. The data show that the difference is due to a more accurate logging procedure at NorthGRIP 2 than at NorthGRIP 1. The improvement is caused by colder temperature conditions during logging, and an optimized handling of the cores.

\section{AGKNOWLEDGEMENTS}

The NorthGRIP project is organized by the Department of Geophysics at the Niels Bohr Institute, University of Copenhagen. It is supported by the National Science Foundations of Denmark, Belgium, France, Germany, Japan, Sweden, Switzerland and the United States of America. We wish to thank those who participated in logging the NorthGRIP ice cores.

\section{REFERENCES}

Dahl-Jensen, D. and 8 others. 2002. The NorthGRIP deep drilling program. Ann. Glaciol., 35 (see paper in this volume).

Gundestrup, N. S., S. J. Johnsen, P. Journé andJ. Schwander. 1996. The EPICA deep ice core drill. In Hempel, G., ed.The ocean and the poles: grand challenges for European cooperation. Stuttgart, Gustav Fischer Verlag, 279-287.

Johnsen, S. J., N. S. Gundestrup, S. B. Hansen, J. Schwander and H. Rufli. 1994. The new improved version of the ISTUK ice core drill. Natl. Inst. Polar Res. Mem., Special Issue 49, 9-23.

Pauer, F., J. Kipfstuhl, W. F. Kuhs and H. Shoji. 1999. Air clathrate crystals from the GRIP deep ice core: a number-, size- and shape-distribution study. F. Glaciol., 45(149), 22-30. 